\title{
An 1-D Integrated Hydro-Mechanical Model to Unravel Different Hydrological Triggering
} Processes of Debris Flows

Theo W.J. van Asch ${ }^{a, b}$, Bin Yu ${ }^{b}$, Wei Hu

a. Faculty of Geosciences, Utrecht University, P.O. Box 80115, 3508 TC, Utrecht, the Netherlands.

b. State Key Laboratory of Geohazard Prevention and Geoenvironment Protection, Chengdu University of Technology, Chengdu, Sichuan, 610059, P.R. China;

t.w.j.vanasch@uu.nl

471174592@qq.com

513933225@qq.com

corresponding author :

Th.W.J. van Asch

Nachtegaalstraat 6

4116 BP Buren

The Netherlands

Tel: 0031344571449

t.w.j.vanasch@uu.nl 


\title{
An 1-D integrated hydro-mechanical model to analyze different hydrological triggering processes of debris flows
}

\begin{abstract}
Many studies, which try to analyze the meteorological threshold conditions for debris flows ignore the type of initiation. This paper focuses on the differences in hydrological triggering processes of debris flows in channel beds of the source areas. The different triggering processes were studied in the laboratory and by model simulation on the field scale. The laboratory experiments were carried out in a flume, $8 \mathrm{~m}$ long and a width of $0.3 \mathrm{~m}$. An integrated hydromechanical model was developed, describing Hortonian and Saturation overland flow, through flow, maximum sediment transport and failure of bed material. The model was tested on the processes observed in the flume. The flume experiments show a sequence of hydrological processes triggering debris flows, namely erosion and transport by intensive overland flow and by infiltrating water causing failure of channel bed material. Model simulations carried out on a schematic hypothetical source area of a catchment show that the type and sequence of these triggering processes are determined by slope angle and the hydraulic conductivity of the bed material. It was also clearly demonstrated that the type of initiation process and the geometrical and hydro-mechanical parameters may have a great influence on rainfall intensity-duration threshold curves, indicating the start of debris flows.
\end{abstract}

Key words: triggering of debris flows; overland flow; infiltration; laboratory experiments; modelling; rain intensity-duration threshold curves 


\section{Introduction}

A debris flow is the most dangerous type of mass movement because depending on the rheology and topography it can reach a very high speed and large run-out distance. Important study aspects are the mechanism and boundary condition of the initiation process of a debris flow, because it determines the meteorological threshold conditions and further evolution and it will provide clues for future mitigation strategies [1].

One can make different classifications of initiation mechanisms based on different viewpoints [1] It was among others [2-3], who stressed the importance of the infiltration capacity of the soil as a key factor for either the development of shallow landslides or surficial erosion and transport of material by overland flow that might create different types of flow like mass movements. We will use this hydrological classification principal in this paper and make a primary distinction between overland flow driven and infiltrating driven initiation mechanisms. Effective overland flow driven triggering processes are mainly concentrated in channels where high water discharges, severe erosion and transport lead to high solid concentrations generating debris flows [4-9]. Material is supplied to these debris flows by detachment and transport of the bed material but also through lateral erosion of the channel bed. The channel can be partly or totally blocked by landslide dams. High run off discharges eroding these landslide dams can also lead to initiation and rapid grow of debris flows ([10-12]. Landslide damming can also be initiated by rapid incision of the channel bed destabilizing the side walls [13]. With infiltrating driven triggering mechanisms, shallow landslides are generated, which may or may not transform into debris flows. This failure mechanism by infiltrating water can occur in channel beds filled with loose material [14] and on planar slopes where shallow landslides can also transform into debris 
flows [15-18]. The transformation of a failed mass into a debris flow is rather complex and depends on various hydro-mechanical processes related to pore pressure development and supply of abundant overland flow water further mobilizing the failed mass ([19-23].

Several authors analyzed partly or more completely the role of hydro-mechanical and morphometric factors controlling the type of initiation of debris flows. Berti [24] analyzed the hydrological factors for the generation of debris flows in typical source areas in the Italian Alps by modelling channel overland in the channel bed from a source area as a response to rainfall impulses. Kean [25] proposed an integrated hydro-geotechnical dynamic model to describe sediment transport by overland flow and consequent mass failure transforming into debris flow surges. $\mathrm{Hu}[26]$ highlighted the initial soil moisture and thus infiltration capacity as a controlling factor on the type of initiation: wet soils created surficial erosion and incision, bank failure, damming and debris flow development and for dry soils landslide failure and debris flows. [1] Zhuang focused more on the slope gradient as a controlling factor for different types of initiation. Their flume studies revealed that at gentler slope gradients around $10^{0} \pm 2^{0}$, incision and bank failure is dominant creating channel damming and dam failure inducing debris flows. At intermediate slopes around $15^{0} \pm 3^{0}$ erosion of bed material occur at high discharges. The high sediment transport capacity with high sediment concentrations is sufficient to create debris flows. At steep slopes around $21^{0} \pm 4^{0}$ bed failure by infiltrating overland flow water with debris flow formation is the most dominant process.

Meteorological thresholds for the initiation of debris flows are closely related to the process of initiation. In many studies about these meteorological thresholds, no clear distinction was made between the types of triggering ([27]. The assessment of these thresholds in relation to various 
morphometric and geological factors was made in most cases using statistical techniques [2830].

One can conclude that important triggering mechanisms occur in the channel of debris flow gullies by overland flow in the source area. The first aim of this paper is to analyze with an integrated 1-D hydro-mechanical model, the boundary conditions (hydraulic conductivity and slope gradient) for the type and sequence of hydrological triggering mechanisms and thus mode of debris flow initiation.

The second aim of this paper is to use this model to analyze in a physical way the effect of the most important morphometric and hydro-mechanical factors on the meteorological threshold for two types of initiation processes of debris flows namely overland flow and bed failure.

\section{Description of the Flume experiments}

A flume was designed to simulate in a 1D frame work the initiation of debris flows by overland flow and through flow (Figure 1). The flume has a length of $8 \mathrm{~m}$ and a width of $0.3 \mathrm{~m}$. The material simulating the channel bed with a thickness of $0.1 \mathrm{~m}$ and a width of $0.3 \mathrm{~m}$ is positioned at a distance of $4 \mathrm{~m}$ from the top of the flume and has a length of $2 \mathrm{~m}$. The material was brought into the flume in layers of about $2 \mathrm{~cm}$ and was slightly compacted (dry density see Table1). There is an outflow at a distance of $2 \mathrm{~m}$ from the lower end of the channel bed (Figure 1). The water is entered at the upper end of the flume with a discharge, which can be controlled simulating run on 


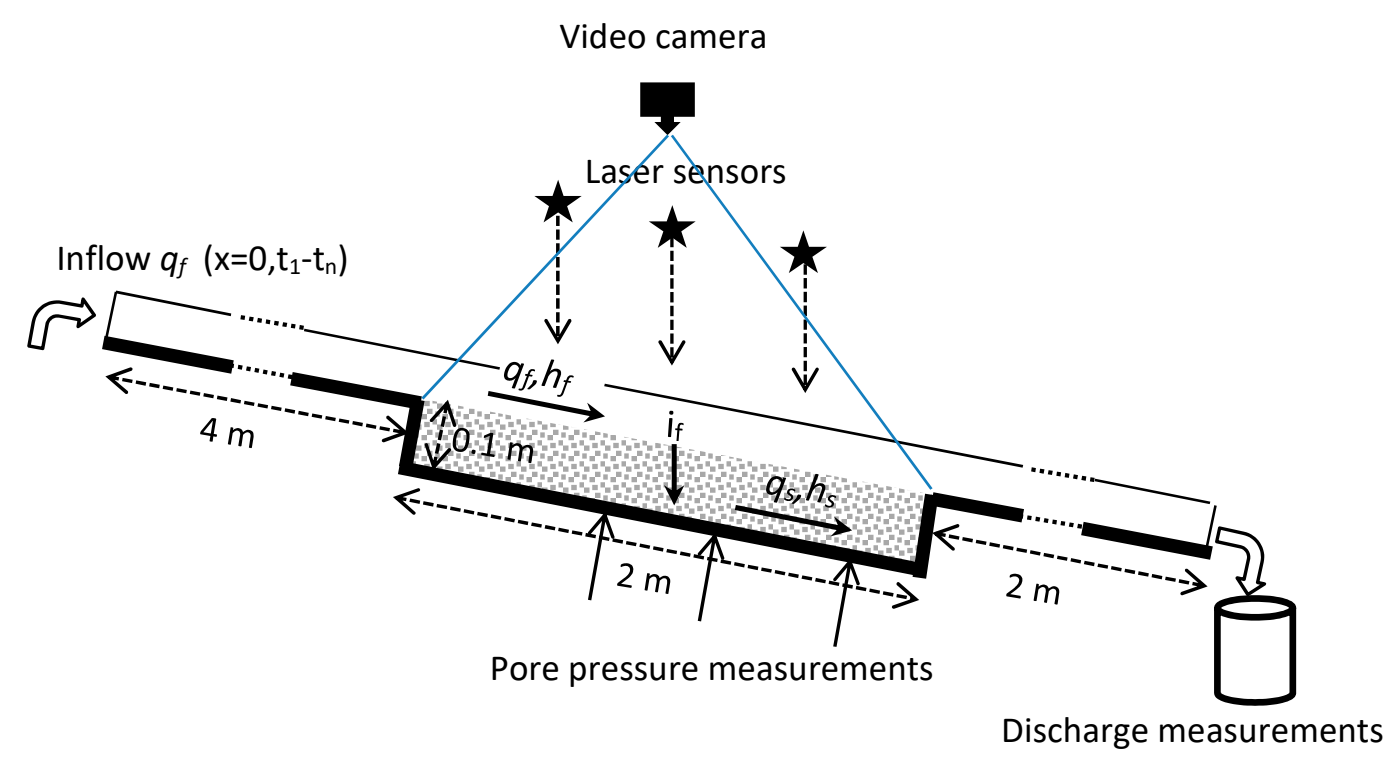

Figure 1: Design of the flume test. For explanation of the parameters see text

\begin{tabular}{|c|c|c|c|c|c|c|}
\hline $\begin{array}{l}\text { Particle size } \\
\text { class }\end{array}$ & $\begin{array}{c}\text { Friction } \\
\phi\left(^{\circ}\right)\end{array}$ & $\begin{array}{l}\text { Density } \\
\mathrm{kNm}^{-3}\end{array}$ & $\begin{array}{l}\text { Hydraulic } \\
\text { conductivity }\left(\mathrm{m} \mathrm{s}^{-1}\right)\end{array}$ & $D_{30}(\mathrm{~mm})$ & $D_{50}(\mathrm{~mm})$ & $\mathrm{D}_{90}(\mathrm{~mm})$ \\
\hline Coarse & 34.6 & 15.4 & 4.91E-03 & 9 & 11 & 18 \\
\hline Medium & 33.7 & 16.3 & $3.28 \mathrm{E}-03$ & 4 & 6 & 16 \\
\hline Fine & 29.2 & 19.5 & $0.54 \mathrm{E}-03$ & 0.7 & 1.6 & 8 \\
\hline
\end{tabular}

Table I. Hydro-mechanical characteristics of three types of bed material, used in the flume tests. Friction means friction angle of the material in degrees. D30 means that $30 \%$ of the sample has a lower diameter than what is indicated in the column (etc).

water from an upstream area. Three types of material were used in the experiments with different grain size distributions (Figure 2). We could vary the slope angle of the flume between $14^{0}$ and $20^{0}$. The initial moisture content of the flume material was more or less dry. The initial moisture 
content is important for the infiltration capacity but since we used in the laboratory a large influx of water from above into coarse bed material, we ignored the effect of the Sorpetivity (related to the initial moisture content) on the infiltration capacity of the bed material.

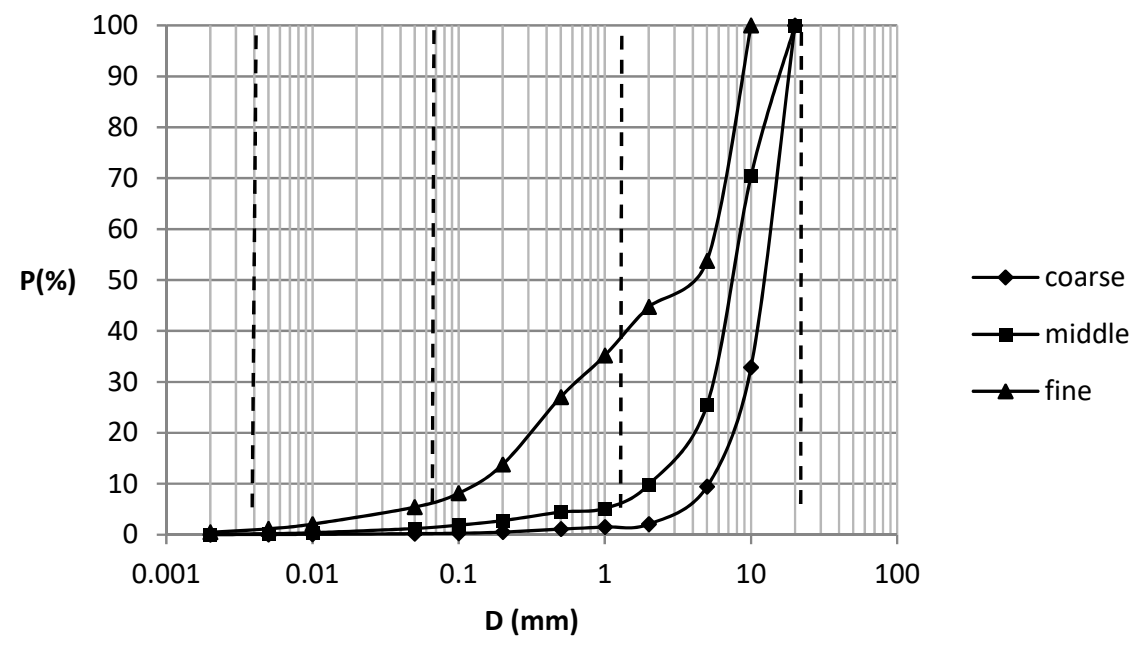

Figure 2: Cumulative grain size distribution of the three bed materials, used in the flume tests

The friction of the three materials was measured with the conventional direct shear apparatus [31] The hydraulic conductivity was measured with a constant-head permeameter. The hydraulic conductivity of saturated cylindrical soil samples of the three grainsizes was measured with a constant head gradient between the upper and lower end of the sample ([32]. Table I gives 
further information about the friction, hydraulic conductivity and gradient of the materials used for the experiments.

Pore pressure was measured at three places (Figure 1) at the bottom of the flume. The pore pressure sensors, type :YP4049, were produced by Yom Technology Company. The measuring range of pore pressure is from $-100 \mathrm{kPa}$ to $100 \mathrm{kPa}$.

Laser sensors (ZLDS100 ZSY Group; resolution $0.03 \%$ FS) at three points with a spacing of 0.5 $\mathrm{m}$ (Figure 1) were used to monitor topographical heights, especially with the aim to monitor abrupt changes in relief due to bed failure.

In addition video-recordings were performed (Figure 1) to follow the sequence of processes in the course of the experiments. During the process of overland flow erosion, samples were taken six times for more or less steady state conditions at the outlet of the Flume (Figure 1). The discharge of water with sediments was collected in baskets during 5 seconds. The sediments were sieved, dried and weighted to measure the concentration of the fluid. An integrated model for surface and sub surface flow, sediment transport and bed slope stability was developed to describe the processes in the flume, which was used later to analyze the sequence of different initiation processes at the field scale.

\section{1D integrated model for debris flow initiation in upstream channels}

First we have to simulate the hydrological part of the triggering mechanism of debris flows. For that we need the mass balance equation for overland (Eq.(1a)) and through flow (Eq.(1b)), which is given by :

$$
\frac{\partial q_{f}}{\partial x}+\frac{\partial h_{f}}{\partial t}=B_{1}
$$


$\frac{\partial q_{s}}{\partial x}+\frac{\partial h_{s}}{\partial t}=B_{2}$

where $q_{f}$ is overland flow discharge per unit width $\left(\mathrm{m}^{3} \mathrm{~m}^{-1} \mathrm{~s}^{-1}\right) ; q_{s}$ is subsurface discharge per unit width $\left(\mathrm{m}^{3} \mathrm{~m}^{-1} \mathrm{~s}^{-1}\right) ; h_{f}$ is thickness of overland flow $(\mathrm{m}) ; h_{s}(\mathrm{~m})$ is thickness of subsurface flow, $\partial x$ (m) is distance along the slope $\partial t$ is the time (s) and $B 1-2$ are terms $\left(\mathrm{m} \mathrm{s}^{-1}\right)$ describing the inflow or outflow of water from the flow system, which is defined as follows:

$B_{1}=\left[\begin{array}{l}r-i_{f}(a) \\ 0-i_{f}(b)\end{array}\right]$

$B_{2}=i_{f}$

where $r\left(\mathrm{~m} \mathrm{~s}^{-1}\right)$ describes the external input of rain into and $i_{f}\left(\mathrm{~m} \mathrm{~s}^{-1}\right)$ the outflow of water by infiltration out of the overland flow system (Eq. (2a)) (see also Figure 1). When there is no supply of rain, like in our flume experiments: $r=0$. In the case of subsurface flow if in Eq.(2b) is considered now as an inflow term of the subsurface flow system. If $h_{f} / \Delta t$ is larger than the infiltration capacity $K s\left(\mathrm{~m} \mathrm{~s}^{-1}\right)$ of the bed material the latter one is the limiting factor. Therefore the infiltration term $i_{f}$ of Eq. (2) is the minimum (min) value of the infiltration capacity $K s\left(\mathrm{~m} \mathrm{~s}^{-1}\right)$ and the current water depth $\left(h_{f}\right)$, which can infiltrate in one time step $\Delta t$ into the bed material:

$i_{f}=\min \left(K s, h_{f} / \Delta t\right)$

We introduce here a general momentum equation for the water flow processes [33]:

$h_{f}=\alpha_{f} q_{f}^{\beta_{f}}$ 
$h_{s}=\alpha_{s} q_{s}^{\beta_{s}}$

For turbulent overland flow the parameters $\alpha_{f}$ and $\beta_{f}$ in Eq.(4a) can be defined as follows :

$\alpha_{f}=\left(\frac{n}{S_{0}{ }^{0.5}}\right)^{0.6}$ and $\beta_{f}=0.6$

where $n$ is Manning's $n$ and $S_{0}$ the slope gradient of the bed material.

For subsurface flow we can write according to Darcy's law:

$q_{s}=K s \sin \theta h_{s} \rightarrow h_{s}=\frac{1}{K s \sin \theta} q_{s}$

where $q_{s}$ is the amount of subsurface flow water per unit width $\left(\mathrm{m}^{3} \mathrm{~m}^{-1} \mathrm{~s}^{-1}\right) ; \theta$ is slope angle (degrees) and $h_{s}$ is the height of the flowing water component in the soil matrix (m). By comparing Eq.(6) with the general momentum Eq. (4b) we can define the parameters $\alpha_{s}$ and $\beta_{s}$ for subsurface flow:

$\alpha_{s}=\frac{1}{K s \sin \theta} \quad$ and $\quad \beta_{s}=1$

A combination of the mass balance Eq.(1) with Eq.(4) delivers an expression for overland flow or subsurface flow discharge $\left(q_{f}, q_{s}\right)$ [33]:

$$
\begin{aligned}
& \frac{\partial q_{f}}{\partial x}+\alpha_{f} \beta_{f} q_{f}^{\left(\beta_{f}, s-1\right)} \frac{\partial q_{f}}{\partial t}=B_{1} \\
& \frac{\partial q_{s}}{\partial x}+\alpha_{s} \beta_{s} q_{s}^{\left(\beta_{s}-1\right)} \frac{\partial q_{s}}{\partial t}=B_{2}
\end{aligned}
$$


The 1D model is implemented in a fixed Eulerian frame where the variation in water flow variables is described at fixed coordinate points at a distance $\Delta x$ along the slope as a function of time step $\Delta t$. A numerical solution for Eq.(8) is given by [33]:

$q_{x+1}^{t+1}=\frac{\frac{\Delta t}{\Delta x} q_{x}^{t+1}+\alpha \beta q_{x+1}^{t}\left(\frac{q_{x+1}^{t}+q_{x}^{t+1}}{2}\right)^{\beta-1}+\Delta t\left(\frac{B_{x+1}^{t+1}+B_{x+1}^{t}}{2}\right)}{\frac{\Delta t}{\Delta x}+\alpha \beta\left(\frac{q_{x+1}^{t}+q_{x}^{t+1}}{2}\right)^{\beta-1}}$

where $\mathrm{q}_{\mathrm{x}}, \alpha$ and $\beta$ should be read as $\mathrm{q}_{\mathrm{f}, \mathrm{s}} \alpha_{\mathrm{f}, \mathrm{s}}$ and $\beta_{\mathrm{f}, \mathrm{s}}$ respectively.

To simulate the initiation of debris flows by mass failure we used the equation for the infinite slope equilibrium model [31], which is the trigger for failure:

$F=\frac{\left(\gamma_{s} z \cos \theta-p\right) \tan \varphi}{\gamma_{s} z \sin \theta}$

$p=\gamma_{w} h_{s} \cos \theta$

where $F$ is the safety factor; failure occurs when $\mathrm{F}=1 ; \gamma_{s}$ and $\gamma_{w}$ are the saturated bulk density of the material and water respectively; $\phi$ is friction angle of the material; $z$ and $h_{s}$ are the thickness of the soil and the height of the groundwater layer respectively $h_{s}$ can be solved with Eq. (9) and Eq.(6) respectively.

The overall stability of the bed material expressed with the safety factor $(F)$ for the infinite slope model is calculated as an average of the safety factor of the different nodes. The inflow of water into the flume is coming from upstream and therefore the pore pressure gradient is decreasing downstream. This means that the safety factor is always increasing downstream and therefore the 
average approach of the safety factor over the length of the sample in the flume seems a reasonable approximation of the overall safety factor.

For estimating the transport capacity on steep slopes Rickenmann [34-35] proposed a bedload transport equation based on a shear stress approach, where discharge, bed slope gradient and material grading are used as parameters to characterize flow hydraulics.

For steeper slopes, in the range of $0.03<\mathrm{S}<0.2\left(1.7^{\circ}-11.3^{\circ}\right)$ Rickenmann [34] performed a regression analysis with the steep flume data on bed load transport obtained at ETH Zurich that resulted in the equation:

$q_{\text {solid }}=\frac{12.6}{\left(d_{s}-1\right)^{1.6}}\left(\frac{D_{90}}{D_{30}}\right)^{0.2}\left(q_{f}-q_{c}\right) S^{2}$

where $D_{90}$ and $D_{30}$ are grain sizes at which $90 \%$ and $30 \%$ respectively by weight of the material are finer; $d_{s}$ is the mass density of the solids and $S$ is the slope gradient and $q_{c}$ is the critical flow discharge for bed load entrainment. The experimental slopes were in the range of $0.03>S>0.20$. $\left(1.7^{0}-11.3^{\circ}\right)$ and the $D_{90}$ of the material ranged between $0.9>$ and $2 \mathrm{~cm}$ and $D_{30}$ between 0,06 and $1 \mathrm{~cm}$ with inflow rates of 10-30 1/s In the paragraph below we will calibrate Eq.(11) for the steeper slopes in our flumes

\section{Results of the flume tests}

\subsection{Initial observations during the flume tests.}

During the flume tests with the three bed materials under different slope angles, observation were carried out by means of video images and the laser sensors regarding the type of overland 
flow initiation, time to overland flow initiation and bed failure, surficial erosion phenomena, critical slope angles for bed failure and type of bed failure (Table II).

\begin{tabular}{|c|c|c|c|c|c|c|}
\hline $\begin{array}{l}\text { Grain size } \\
\text { D50 }\end{array}$ & Slope & $\begin{array}{l}\text { Inflow } \\
\left(\mathrm{l} / \mathrm{s}^{-1} \mathrm{~m}^{-1}\right)\end{array}$ & $\begin{array}{l}\text { Time to overland } \\
\text { flow initiation (s) }\end{array}$ & & $\begin{array}{c}\text { Time to bed } \\
\text { failure (s) }\end{array}$ & \\
\hline \multirow{2}{*}{ Coarse } & $20^{\circ}$ & 0,18 & 402 & & 411 & \\
\hline & $18^{0}$ & 0,22 & 103 & 33 & 110 & \\
\hline \multirow{3}{*}{$11 \mathrm{~mm}$} & $16^{0}$ & 0,29 & 63 & & 72 & \\
\hline & $15^{0}$ & 0,40 & 73 & & & \multirow{2}{*}{$\mathrm{nf}$} \\
\hline & $14^{0}$ & 0,41 & 59 & & & \\
\hline \multirow{2}{*}{ Medium } & $20^{\circ}$ & 0,11 & 168 & a & 168 & \\
\hline & $18^{0}$ & 0,13 & 140 & & 140 & \\
\hline \multirow{3}{*}{$6 \mathrm{~mm}$} & $16^{0}$ & 0,16 & 54 & & 106 & \\
\hline & $15^{0}$ & 0,18 & 27 & 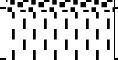 & & \multirow[t]{2}{*}{ nf } \\
\hline & $14^{0}$ & 0,19 & 46 & 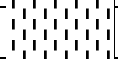 & & \\
\hline \multirow{2}{*}{ Fine } & $20^{\circ}$ & 0,03 & 30 & h & 270 & \multirow{2}{*}{ 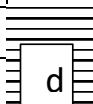 } \\
\hline & $18^{0}$ & 0,06 & 220 & & 613 & \\
\hline \multirow{3}{*}{$1.6 \mathrm{~mm}$} & $16^{0}$ & 0,09 & 90 & $\begin{array}{ll}0 \\
0\end{array}$ & 270 & \\
\hline & $15^{0}$ & 0,10 & 110 & $\begin{array}{l}n \\
0\end{array}$ & & \\
\hline & $14^{0}$ & 0,11 & 102 & 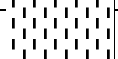 & & \\
\hline
\end{tabular}

Table II. Observed time to overland flow and bed failure, overland flow type and failure mode in flume experiments for three types of bed material and for different bed slope angles: a) Saturation overland flow; b) Hortonian overlandflow; c) slow continuous bed failure; d) rapid failure; $n f$ : no failure.

In slope hydrology two types of overland flow can be distinguished: Saturation overland flow and Hortonian overland flow [32]. These two types could be distinguished during the different flume experiments (Table II). Saturation overland flow was characterized, after complete saturation of the soil, by a more or less spatially randomly ponding of water at the soil surface, while Hortonian overland flow, which occurs when the rainfall intensity or supply of overland flow water is larger than the infiltration capacity of the soil, showed a more concentrated continuous flow all over the flume According to these visual indicators we could establish a 
boundary between Saturation overland flow and Hortonian overland flow, which in our flume tests was found in the medium grain size materials at a slope gradient of $16^{0}$ (Table II). This could be verified with our model simulation (see below paragraph 4.2). For courser materials (Ks values of $4.19 \mathrm{E}-03$ and $\left.3.28 \mathrm{E}-03 \mathrm{~m} \mathrm{~s}^{-1}\right)$ and higher slope angles $\left(>16^{0}\right)$ the time to Saturation overland flow is immediately followed by failure or with a small delay until 9 seconds. Also one can clearly observe that the time to Saturation overland flow (and thus failure) is decreasing with decreasing slope angle (Table II) .

Hortonian overland flow [32].was initiated in most cases on the finer sediments, which is ascribed to the lower infiltration capacity $\left(\mathrm{Ks}=0.54 \mathrm{E}-03 \mathrm{~m} \mathrm{~s}^{-1}\right)$. Bed failure in this case occurred a certain time after the start of the Hortonian overland flow with a time lag ranging between 35 and 160 seconds (Table II), because in this case, due to the lower percolation rate it takes time to bring the groundwater in the bed material to a critical failure level.

Bed failure initiation is controlled by the bed gradient and the internal friction of the material and occurred in our experiments on slopes of approximately 16 degrees and higher. At lower slope angles no bed failure occurred (nf in Table II) and sediment delivery occurred only by overland flow erosion

The medium and course materials show bed failure characterized by slow movements over the total depth combined with fast surficial entrainment of grains by saturated overland flow. Movement of bed material is slow and continuous or sometimes intermittent showing a surging pattern (Table II). Instead of the slow and more flow like movements observed for the medium and coarse sediments, failure of the fine sediments occurred suddenly with a very rapid surge of more or less coherent blocks followed by fluidization, (Table II) . 
Sediment transport by overland flow on these steep slopes reached volumetric concentrations between 0.46 and 0.64 which is characteristic for debris flows

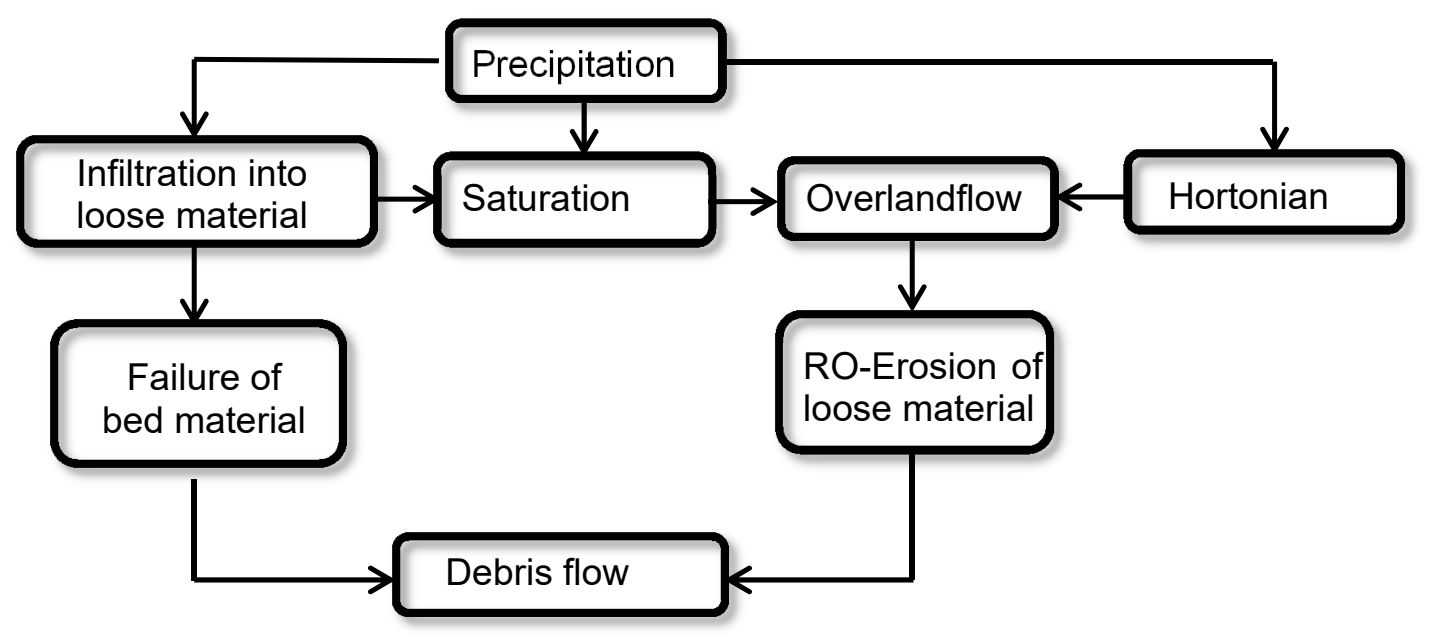

Fig 3 schematic diagram showing the different initiation processes of debris flows in channels

We can conclude on the basis of these observations that the flume tests carried out with the three materials revealed three types of processes, which created debris flows on these range of slopes gradients namely debris flow Initiation by Hortonian Overland flow Erosion (RhE-I), Saturation Overland flow Erosion (RsE-I) and by Bed Failure (BF-I). The occurrence and sequence of these processes seems to be controlled by slope gradient and hydraulic conductivity of the bed sediment. Figure 3 gives a schematic overview of these process types.

\subsection{Modelling the flume test processes}

The next step was to model some of the processes in the flume. We used a number of process indicators from the flume experiments to validate the outcomes of our model. These are : 
Saturation or Hortonian overland flow, time to overland flow, maximum pore pressure, time to bed failure and solid concentration by overland flow erosion. Hortonian overland flow and the time to Hortonian overland flow in the model is declared when surface water $h_{f}$ reaches the lower end of the bed material while the bed material is still not satured $\left(h_{s}<Z s\right)$.Saturation overland flow and the time towards it, is declared when $h_{s}=Z s$ over the entire bed. Pore pressure is calculated each time step according to Eq (10b). The discharge of $h_{f}+h_{s}$ is reported each time step at the end of the flume. Bed failure is declared as said before when the average Safety factor $F$ over the bed length reaches the value of 1

For the flume simulations the distance between the nodes $(\Delta x)$ was $0.1 \mathrm{~m}$ and the time interval ( $\Delta t)$ was 0.2 seconds.

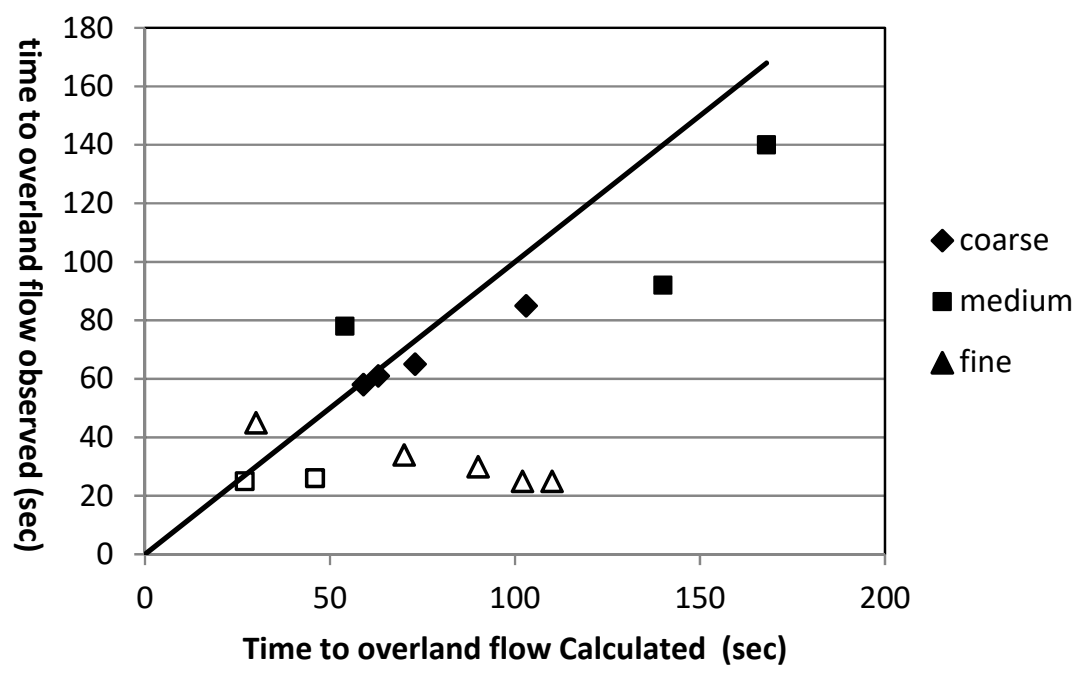

Figure 4 Observed and calculated time to Saturation overland flow (black symbols) and Hortonian overland flow (open symbols)

Figure 4 shows the relation between observed and calculated time to overland flow for the different flume tests. There is a moderate 1:1 correlation between observed and predicted time to 
overland flow for the medium and coarse sediments and for the fine sediments, showing Hortonian overland flow, there is no correlation at all. However the model was able to predict the type of overland flow according to what was observed during the flume tests (see Table II).

Despite the malfunctioning of some pore pressure sensors we were able to make an 1:1 comparison between the average maximum measured pore pressure for the three sensors (Figure 1) and the average calculated maximum pore pressure (Figure 5).

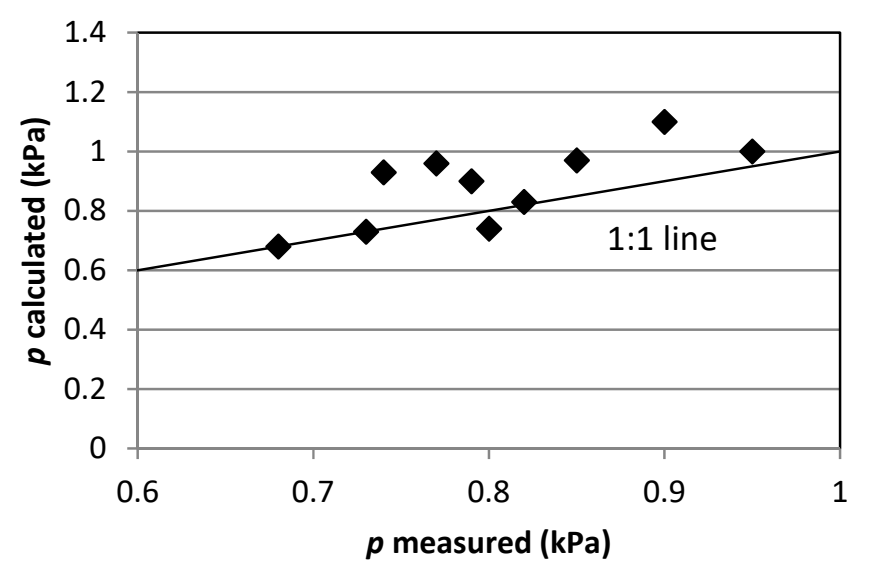

Fig 5 Maximum pore pressure measured during flume tests in relation to calculated pore pressures.

The Figure shows that in many cases there is a slight overestimation of the calculated pore pressure. Time series of measured pore pressure of the three sensors compared to modelled temporal pore pressure development showed that in most cases the onset towards maximum pore pressure for the three sensors is more irregular compared to the calculated development of the pore pressures (Figure 6). This can be ascribed to the heterogeneity of the sediment or (and) the imperfect response of the sensors 


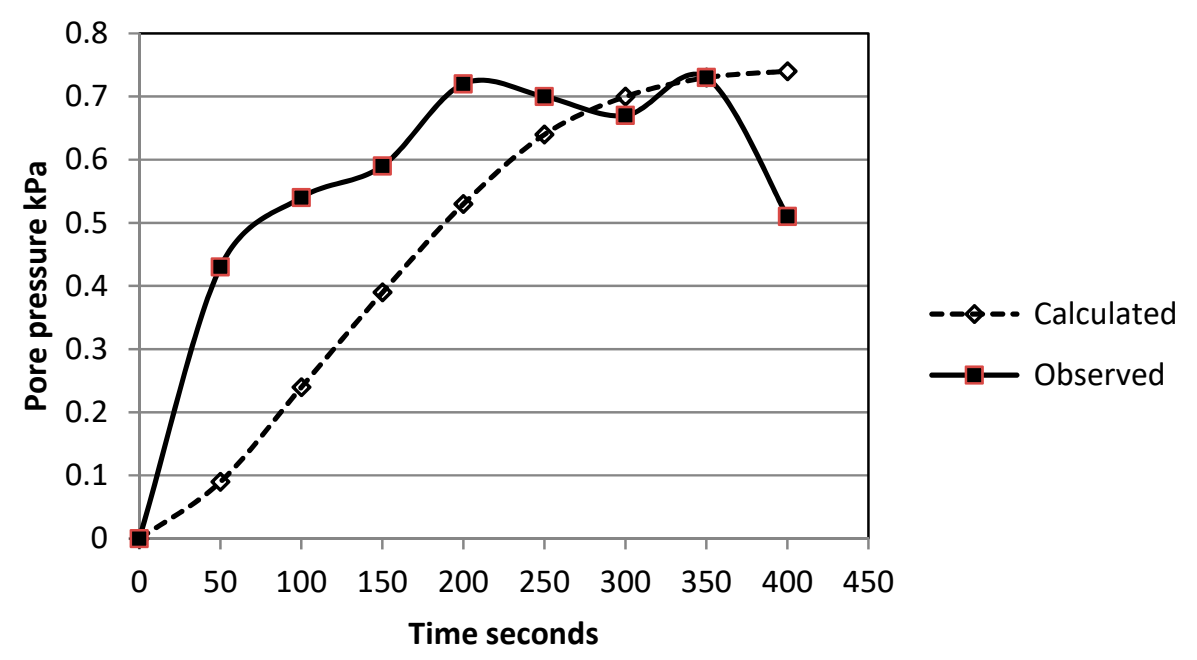

Fig 6 Example of the rise in pore pressure (measured/calculated) due to infiltration of run-on water in the bed material (Test:Medium grain size $/ 20^{\circ}$ )

In relation to pore pressure development we compared the time to failure for the different test runs on the different materials. Since the time towards average maximum calculated and measured pore pressure coincided more or less, one would expect also corresponding calculated and measured failure times. Table II and Figure 7 show that the match between observed and calculated failure time is reasonable except for two outliers (coarse- $20^{0}$; fine- $18^{0}$ ). Further we can observe that the calculated time to failure is underestimated for the coarse material and overestimated for practically all the tests on the medium and fine materials. The deviations between calculated and observed values must be ascribed to heterogeneity of the material, deviating friction values, and incorrect assessment of the overall safety factor 


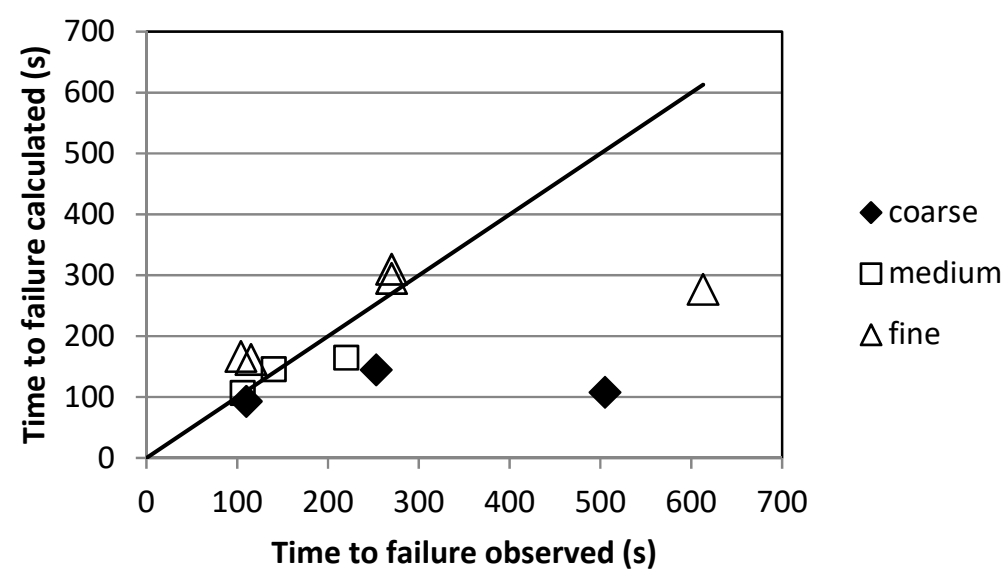

Figure 7: Observed and calculated time of failure of bed material during the flume tests.

We calibrated also the parameters of the Rickenmann [35] equation, (Eq.11) on our flume tests, which were carried out on slopes ranging between $0.25>S>0.36\left(14^{0}-20^{0}\right)$, with grain sizes for $0.9>d_{90}>2$ and $0,05>d_{30}>1 \mathrm{~cm}$ and with flow rates $0,5>q_{f}>151 \mathrm{~s}^{-1} \mathrm{~m}^{-1}$. Figure 8 shows the best linear fit between $q_{\text {solid }} / q_{\mathrm{f}}$ and $\left(d_{90} / d_{30}\right)^{0.2} S^{2}$, which delivered the following modified equation for slopes between $14^{0}$ and $20^{\circ}$ :

$q_{\text {solid }}=7.28\left(\frac{D_{90}}{D_{30}}\right)^{0.2} q_{f} S^{2}$

which gives for $d_{s}=2.6$ :

$q_{\text {solid }}=\frac{15.44}{\left(d_{s}-1\right)^{1.6}}\left(\frac{D_{90}}{D_{30}}\right)^{0.2} q_{f} S^{2}$ 


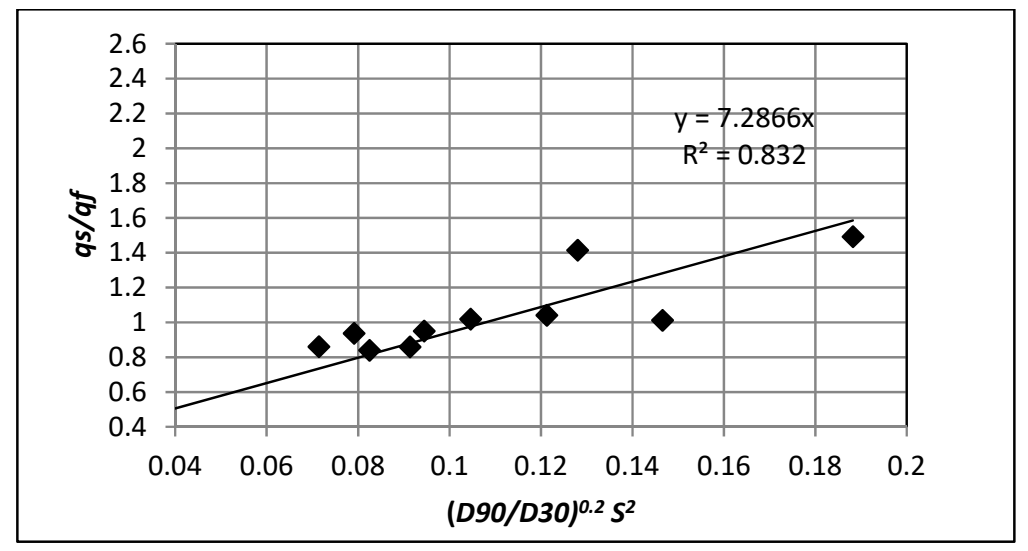

Figure.8. Calibration of Rickenmann's bedload equation for steeper slopes in our flume tests between 14 and 20 degrees.

The calibration revealed that $q_{\mathrm{c}}$ in Eq.(11) becomes zero or practical zero in Eq.(12). At slopes larger than $15^{\circ}$ the down slope component of the grain weight may reduce the critical shear stress $\tau_{c}$ which in our case obviously reduced to nearly zero

\section{Sensitivity analyses at the field scale}

\subsection{A schematic source area for sensitivity analyses at the field scale}

To study the influence of terrain parameters and the hydro-mechanical parameters on debris flow initiation a schematic source area of a catchment is proposed here. Figure 9 shows this schematic source area, which is linked to an upstream channel filled with bed material receiving surface water from the surrounding slopes to initiate a potential debris flow. This geomorphological setting resembles more or less the source areas described among others by Coe [7] and Berti [24]. The upstream area of our hypothetical catchment has a radius $R$. The channel is further surrounded by lateral slopes with a length $L$. The length of the channel bed is $L x$, the width $W$ 
and the slope angle is $\theta$.The hydraulic conductivity of the bed material is $K s$ the porosity Por and the friction angle $\phi$. (Figure 9).

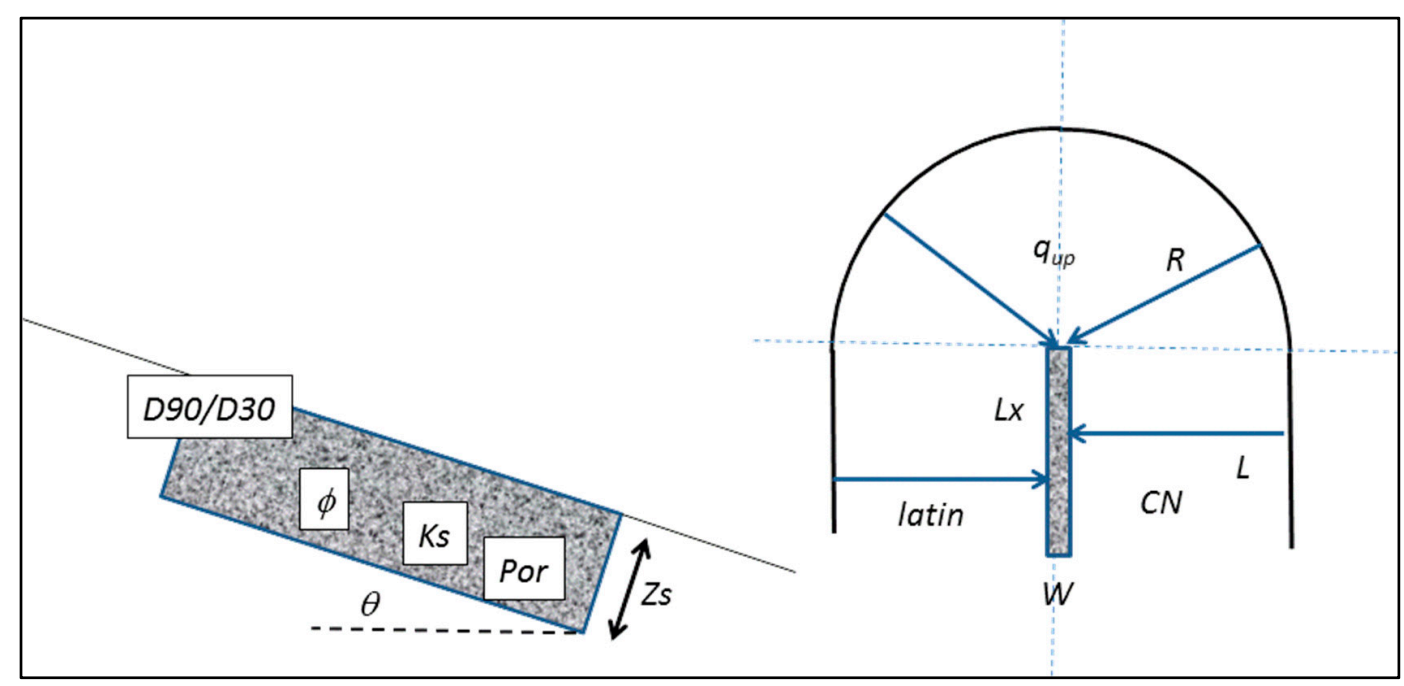

Figure 9: Morphometric and hydro-mechanical parameters, which were used for model simulations of debris flow initiation. For an explanation see Table 3 and text. D90/D30: 90\% and $30 \%$ lower than grainsize D90 and D30 respectively : $\phi$ : friction angle; Ks: hydraulic conductivity; Por :porosity; Zs: depth of material; $\theta$ : slope angle, qup: water that flows into the upper end of the channel bed; $R$ : radius of source area above the channel; Lx and $W$ : length and width of the channel bed; L: length of lateral contributing slope; latin: lateral inflow of water to the channel; CN: curve number value for the soil hydrological and land use characteristics of the contributing slopes.

The sink term $B$ in (1) and (8) is now adapted to the field scene and given by:

$B=2$ latin $+r-i_{f}$

where latin $\left(\mathrm{m} \mathrm{s}^{-1}\right)$ is the lateral inflow of overland flow water from the slopes along the channel (Figure 9), $r$ direct rain intensity input to the channel bed and $i_{f}$ infiltration rate into the bed (see 
Eq.(3)). The lateral inflow is calculated for these sensitivity analyses in a simple way, assuming steady state conditions in the mass balance equation for overland flow:

latin $=\frac{r_{c n} L}{W}$

$r_{c n}(\mathrm{~m} / \mathrm{s})$ is calculated using the Curve Number method [36], $L$ is the length of the lateral slope and $\mathrm{W}$ the width of the channel (see Figure 9). In our simulations we selected overland flow supplying slopes with soils with moderate to slow infiltration rates and a poor condition grass cover, which corresponds to a Curve Number(CN) of about 80 . The $\mathrm{CN}$ number, reflecting the hydrological soil characteristics, land use and antecedent soil moisture conditions that we can expect in high mountainous areas, was chosen arbitrarily and was kept constant in our simulations. The overland flow water that flows into the upper end of the channel bed is given by $q_{u p}\left(\mathrm{~m}^{2} \mathrm{~s}^{-1}\right)$ (Figure 9)

$q_{u p}=\frac{r_{c n} 0.5 \pi R^{2} \cos \theta}{W}$

5.2 The influence of the hydraulic conductivity $(K s)$ and slope $(\theta)$ of the channel bed on the type and sequence of hydrologic triggering processes for debris flows

In the flume we could observe the effect of slope angle and hydraulic conductivity on the type and sequence of triggering processes which may lead to the initiation of debris flows. In this paragraph we will investigate through model simulation the effect of these two factors on the catchment scale. The values of the other factors used in our model simulations are shown in bold as default parametric values (Zs, $\phi, W, L x$, Por.R.L, $n$ bed) in Table III (see also Figure 9). 


\begin{tabular}{|l|l|l|l|}
\hline Ks for $R E-I$ & $0.001-0.0025-0.005 \mathrm{~m} \mathrm{~s}^{-1}$ & Lx & $50-100-200 \mathrm{~m}$ \\
\hline Ks for BF-I & $0.001-0.01-0.1 \mathrm{~ms}^{-1}$ & Por & $0.4-0.3-0.2$ \\
\hline$Z s$ & $2-4-6 \mathrm{~m}$ & $\boldsymbol{R}$ & $250-350-450 \mathrm{~m}$ \\
\hline $\boldsymbol{\phi}$ & $28-32-36$ & $\boldsymbol{L}$ & $250-350-450 \mathrm{~m}$ \\
\hline $\boldsymbol{\theta}$ & $16^{\circ}-20-28^{\circ}$ & $\boldsymbol{n}$ bed & $\mathbf{0 . 0 8}$ \\
\hline $\boldsymbol{W}$ & $2-4-6-\mathrm{m}$ & & \\
\hline
\end{tabular}

Table III. Default values (bold italic) and maximum and minimum values of input parameters for Overland flow Erosion (RE-I) and Bed Failure (BF-I) triggering debris flows. Ks: saturated hydraulic conductivity; Zs: thickness of bed material; $\phi$ friction angle of material; $\theta:$ slope angle of channel bed; $W$ and $L x$ :width and length of channel bed respectively; Por: available volumetric pore space; $R$ radius of source area ; L: length of lateral slopes ; $n$ : Manning's $n$ of bed material.

The data shown in Table IV are obtained from our modelling scenarios as explained in Paragraph 4.2. Table IV gives an overview of the range in $K s$ values (first row) and bed slope angles (first column), which were used in our simulations to study the effect of these parameters on the hydro-mechanical process development at the catchment scale. For these simulations two rain scenarios were used with an intensity of $80 \mathrm{~mm}$ (Table IVa) and $40 \mathrm{~mm}$ per hour (Table IVb) respectively. The Tables show domains with different shades of gray with various combinations of hydro-mechanical triggering processes. In the white sections no debris flow initiation is expected to develop in the source area because of a too low sediment concentration of the overland flow. Table IVa shows that in the domain $\theta=28^{0}-20^{0}$ and $K S=0.001-0.005 \mathrm{~m} \mathrm{~s}^{-1}$, the debris flow is initiated in the first stage by Hortonian overland flow erosion $\left(R_{h} E-I\right)$. The overland flow discharge reaches a steady state after a certain relatively short time. During the steady state groundwater will rise by infiltration of run-on water until failure of the bed material, which happens between 1.7 and 11.2 minutes depending on the slope $\theta$ and $K s$. In Table IVa we 
see a dramatic drop in discharge between slopes with $\mathrm{Ks}=0.001$ and 0.005 . The last value reaches a significant boundary which determines whether or not debris flow can be initiated by Hortonian overland flow transport.

\begin{tabular}{|c|c|c|c|c|c|c|c|c|c|c|}
\hline $80 \mathrm{~mm}$ & Ks & 0.001 & $s^{-1}$ & 0.005 & & 0.01 & & $0.1 \mathrm{~m}$ & & \\
\hline $\begin{array}{l}\text { Slope } \\
\text { degrees }\end{array}$ & $\begin{array}{l}\text { Initiat } \\
\text { proc. }\end{array}$ & $\begin{array}{l}\text { Time } \\
\text { min. }\end{array}$ & $\begin{array}{l}\text { Dischar } \\
\text { I } \text { }^{-1}\end{array}$ & $\begin{array}{l}\text { Time } \\
\text { min. }\end{array}$ & $\begin{array}{l}\text { Dischar } \\
{\text { Is } m^{-1}}\end{array}$ & $\begin{array}{l}\text { Time } \\
\text { min. }\end{array}$ & $\begin{array}{l}\text { Dischar } \\
{\text { I } s m^{-1}}^{2}\end{array}$ & $\begin{array}{l}\text { Time } \\
\text { min. }\end{array}$ & $\begin{array}{l}\text { Dischar } \\
\text { I } s \text { m }^{-1}\end{array}$ & $\begin{array}{l}\text { Concent } \\
I^{-1}\end{array}$ \\
\hline 28 & $\begin{array}{l}\mathrm{R}_{\mathrm{h}} \mathrm{E}-\mathrm{I} \\
\mathrm{BF}-\mathrm{I}\end{array}$ & $\begin{array}{l}1.0 \\
5.4\end{array}$ & 912 & $\begin{array}{l}1.3 \\
1.7\end{array}$ & 139 & 2.4 & & 3.0 & & 0.47 \\
\hline 24 & $\begin{array}{l}\mathrm{R}_{\mathrm{h}} \mathrm{E}-\mathrm{I} \\
\mathrm{BF}-\mathrm{I}\end{array}$ & $\begin{array}{l}1.0 \\
8.4 \\
\end{array}$ & 783 & $\begin{array}{l}1.3 \\
2.3\end{array}$ & 119 & 2.8 & & 3.1 & & 0.39 \\
\hline 20 & $\begin{array}{l}\mathrm{R}_{\mathrm{h}} \mathrm{E}-\mathrm{I} \\
\mathrm{BF}-\mathrm{I}\end{array}$ & $\begin{array}{l}1.1 \\
11.2 \\
\end{array}$ & 683 & $\begin{array}{l}1.4 \\
2.9\end{array}$ & 104 & 3.1 & & 3.1 & & 0.30 \\
\hline 16 & $\begin{array}{l}R_{h} E-I \\
R_{s} E-I\end{array}$ & $\begin{array}{l}1.1 \\
14.2\end{array}$ & $\begin{array}{l}606 \\
732\end{array}$ & $\begin{array}{l}1.5 \\
3.7\end{array}$ & $\begin{array}{l}92 \\
733\end{array}$ & 3.7 & 732 & 3.6 & 705 & 0.21 \\
\hline 12 & $\begin{array}{l}R_{h} E-I \\
R_{s} E-I\end{array}$ & $\begin{array}{l}1.2 \\
14.8\end{array}$ & $\begin{array}{l}550 \\
666\end{array}$ & $\begin{array}{l}1.5 \\
3.9\end{array}$ & $\begin{array}{l}83 \\
665\end{array}$ & 3.8 & 664 & 3.6 & 646 & 0.13 \\
\hline
\end{tabular}

a

\begin{tabular}{|c|c|c|c|c|c|c|c|c|c|c|}
\hline $40 \mathrm{~mm}$ & Ks & 0.00 & $m s^{-1}$ & 0.0 & $5 \mathrm{~m} \mathrm{~s}^{-1}$ & 0.0 & $m s^{-1}$ & & $m s^{-1}$ & \\
\hline $\begin{array}{c}\text { Slope } \\
\text { degrees }\end{array}$ & $\begin{array}{c}\text { Initiat } \\
\text { proc. }\end{array}$ & $\begin{array}{l}\text { Time } \\
\text { min. }\end{array}$ & $\begin{array}{l}\text { Dischar } \\
\text { I } s m^{-1}\end{array}$ & $\begin{array}{l}\text { Time } \\
\text { min. }\end{array}$ & $\begin{array}{l}\text { Dischar } \\
\text { Is } m^{-1}\end{array}$ & $\begin{array}{l}\text { Time } \\
\text { min. }\end{array}$ & $\begin{array}{l}\text { Dischar } \\
{\text { I } s m^{-1}}^{-1}\end{array}$ & $\begin{array}{l}\text { Time } \\
\text { min. }\end{array}$ & $\begin{array}{c}\text { Dischar } \\
\text { Is } m^{-1}\end{array}$ & $\begin{array}{c}\text { Concent } \\
\qquad\left.\right|^{-1}\end{array}$ \\
\hline 28 & $\begin{array}{l}\mathrm{R}_{\mathrm{h}} \mathrm{E}-\mathrm{I} \\
\mathrm{BF}-\mathrm{I}\end{array}$ & $\begin{array}{l}1.5 \\
5.8\end{array}$ & 162 & 7.2 & & 7.9 & & 8.0 & & 0.47 \\
\hline 24 & $\begin{array}{l}R_{h} E-I \\
B F-I \\
\end{array}$ & $\begin{array}{l}1.6 \\
8.8 \\
\end{array}$ & 139 & 7.8 & & 8.2 & & 8.3 & & 0.39 \\
\hline 20 & $\begin{array}{l}R_{h} E-I \\
B F-I\end{array}$ & $\begin{array}{c}1.7 \\
11.7 \\
\end{array}$ & 121 & 8.5 & & 8.5 & & 8.4 & & 0.30 \\
\hline 16 & $\begin{array}{l}R_{h} E-I \\
R_{s} E-I\end{array}$ & $\begin{array}{c}1.8 \\
14.8 \\
\end{array}$ & $\begin{array}{l}108 \\
234\end{array}$ & 9.5 & 235 & 9.4 & 233 & 9.3 & 208 & 0.21 \\
\hline 12 & $\begin{array}{l}R_{h} E-I \\
R_{s} E-I\end{array}$ & $\begin{array}{c}1.9 \\
15.0\end{array}$ & $\begin{array}{c}98 \\
214\end{array}$ & 9.6 & 213 & 9.5 & 212 & 9.2 & 170 & 0.13 \\
\hline
\end{tabular}

b

Table IV. Time sequence of different initiation processes $R_{h} E-I$ and $R_{s} E-I$,(erosion by Hortonian and Saturation overland flow respectively) and BF-I (bed failure) in relation with hydraulic conductivity (Ks) and slope angle of bed material. Further are given the discharge (Discharg) and solid concentration (Concent) during $R_{h} E-I$ and $R_{s} E-I$. Table $4 a$ and $4 b$ : simulated rain intensities of $80 \mathrm{~mm}$ and $40 \mathrm{~mm}$ respectively. 
It is confirmed by Table IVb with a lower rain input $(40 \mathrm{~mm})$ where at $K s \geq 0.005$, no initiation by Hortonian overland flow is possible anymore.

Going back to Table IV-a: in the domain $\theta=16^{0}-12^{0}$ and $K s=0.001-0.005 \mathrm{~ms}^{-1}$ slope failure does not occur. The debris flow is initiated by overland flow. First by Hortonian overland flow and later when the groundwater has reached the surface by Saturation overland flow. Discharge is relatively low when there is Hortonian overland flow, while obviously discharge dramatically increases at Saturation overland flow. However due to the lower slope angles, the volumetric sediment concentration is low $\left(0.21\right.$ at $16^{\circ}$ and 0.13 at $12^{\circ}$, (Table IV-a last column ), which means the flow changes from a hyper concentrated flow into a water flood with conventional suspended load and bed load.

At higher conductivities in the domain $K s=0.01-0.1 \mathrm{~m} / \mathrm{s}$ and $\theta=28^{\circ}-20^{\circ}$, bed failure seems the most dominant process (Table IVa). Due to the larger $K s$ values, infiltration into the bed is more important than overland flow discharge. The bed material turns out to be partly saturated in the upper part due to the larger upstream inflow, creating partly Saturation overland flow and Hortonian overland flow. However within one minute after the run off discharge reached the lower end of the bed, failure of the bed material occurred already. Therefore the contribution of overland flow to the transport of debris by overland flow can be ignored.

In the domain $K s=0.01-0.1 \mathrm{~m} / \mathrm{s}$ and lower slope gradients $\left(\theta=16^{\circ}-12^{\circ}\right)$ there is no slope failure but only Saturation overland flow, (Table IVa ) with low sediment concentrations in most cases not enough to call it a debris flow.

Table IV-b shows the simulation results with an intensity of $40 \mathrm{~mm}$ per hour. The domains with a specific combination of hydro-mechanical triggers still exist. There is only a shift of the boundary for the $K s$-values with no Hortonian overland flow $(>0.005 \mathrm{~m} / \mathrm{s})$ to the left. The Tables 
IVa and $\mathrm{b}$ show a decrease in overland flow discharge and increase in time to bed failure with a decreasing slope angle. Around 16 degrees the channel bed is stable but still steep enough to have transport capacities with concentrations in the domain of a hyper concentrated flow. These are induced by Hortonian and Saturation overland flow at lower Ks values and only Saturation overland flow at higher Ks values. At lower slope angles (see slopes around 12 degrees) sediment concentrations are too low to call it a debris flow. Table $\mathrm{V}$ gives a summary of the type and sequence of initiation processes related to different Ks and slope angle values.

\begin{tabular}{|c|c|c|c|c|c|c|}
\hline $40 \mathrm{~mm}$ & Ks values & $0.001 \mathrm{~m} \mathrm{~s}^{-1}$ & $0.005 \mathrm{~ms}^{-1}$ & $0.01 \mathrm{~m} \mathrm{~s}^{-1}$ & $0.05 \mathrm{~m} \mathrm{~s}^{-1}$ & $0.1 \mathrm{~m} \mathrm{~s}^{-1}$ \\
\hline Gradient & Flow type & \multicolumn{2}{|c|}{ Initiation process } & \multicolumn{3}{|c|}{ Initiation process } \\
\hline $28^{\circ}$ & \multirow{3}{*}{ Debris flow } & \multirow{3}{*}{\multicolumn{2}{|c|}{$\begin{array}{l}\text { t1:Hortonian overland } \\
\text { flow } \\
\text { t2:Bed failure }\end{array}$}} & \multirow{3}{*}{\multicolumn{3}{|c|}{ t1: Bed failure }} \\
\hline $24^{\circ}$ & & & & & & \\
\hline $20^{\circ}$ & & & & & & \\
\hline $16^{\circ}$ & $\begin{array}{l}\text { Hyper } \\
\text { concentrated } \\
\text { flow }\end{array}$ & $\begin{array}{l}\text { t1:Hortonia } \\
\text { flow } \\
\text { t2:Saturatic } \\
\text { flow }\end{array}$ & $\begin{array}{l}\text { n overland } \\
\text { n overland }\end{array}$ & t1:Saturat & n overland & \\
\hline $12^{\circ}$ & $\begin{array}{l}\text { No debris } \\
\text { flow }\end{array}$ & $\begin{array}{l}\text { t1:Hortonia } \\
\text { flow } \\
\text { t2:Saturatic } \\
\text { flow }\end{array}$ & $\begin{array}{l}\text { n overland } \\
\text { n overland }\end{array}$ & t1:Saturat & n overland & \\
\hline
\end{tabular}

Table V: Sequence of different initiation processes for debris (hyper concentrated) flows in relation to the hydraulic conductivity and slope of the channel bed material. Simulated rain intensity is $40 \mathrm{~mm}$. 


\subsection{Factors influencing rain Intensity-Duration (I-D) threshold curves for different} initiation processes of debris flows

In the foregoing we revealed the influence of $K s$ and bed slope gradient on the sequence of two main processes mechanisms involved in the initiation of debris flows. We want to investigate here the effect of the other parameters (including $K s$ and slope gradient) on rainfall thresholds in terms of Intensity Duration (I-D) curves for the triggering of debris flows by these two process mechanism: initiation by Hortonian overlandflow $\left(\mathrm{R}_{h} \mathrm{E}-\mathrm{I}\right)$ and bed failure $(\mathrm{BF}-\mathrm{I})$. As we have seen in Table IV and V, debris flow initiation by Saturation overland flow $\left(\mathrm{R}_{\mathrm{s}} \mathrm{E}-\mathrm{I}\right)$ can only take place around 16 degrees At lower slope angles sediment concentrations are too low to call it a debris flow (Table IV). At higher slope angles we have bed failure before Saturation overland flow can take place. Figure 10 shows the effect of different parameters on the I-D curves for debris flows initiated by Hortonian overland flow. The intensity and duration value of a rain event which creates overland flow that just reaches the end of the channel bed with a sediment concentration of $>0.2$, is defined by us as a threshold rain event for debris flow initiation. The intensity and duration values for a variety of different critical rain events were plotted in a graph with on the y-axis the intensity and on x-as the duration. In this way an Intensity Duration (ID) curve can be constructed. Table III gives an overview of the range of the different parameters and the default values (in bold italic), which were used in the simulation and which give a realistic representation of geometric and geotechnical parameters for source area conditions The threshold curves for debris flow initiation by Hortonian overland flow are shown in Figure 10. In this figure the threshold curves which are constructed, using the default values given in table III, are depicted with open rectangular markers. They are equal in all the sub-figures. This enables one to compare for the different parameters the difference between the ultimate curves and the 
default curve. For each combination of selected parameters there is an ultimate minimum rain intensity below which not enough overland flow and thus a debris flow can be initiated, irrespective
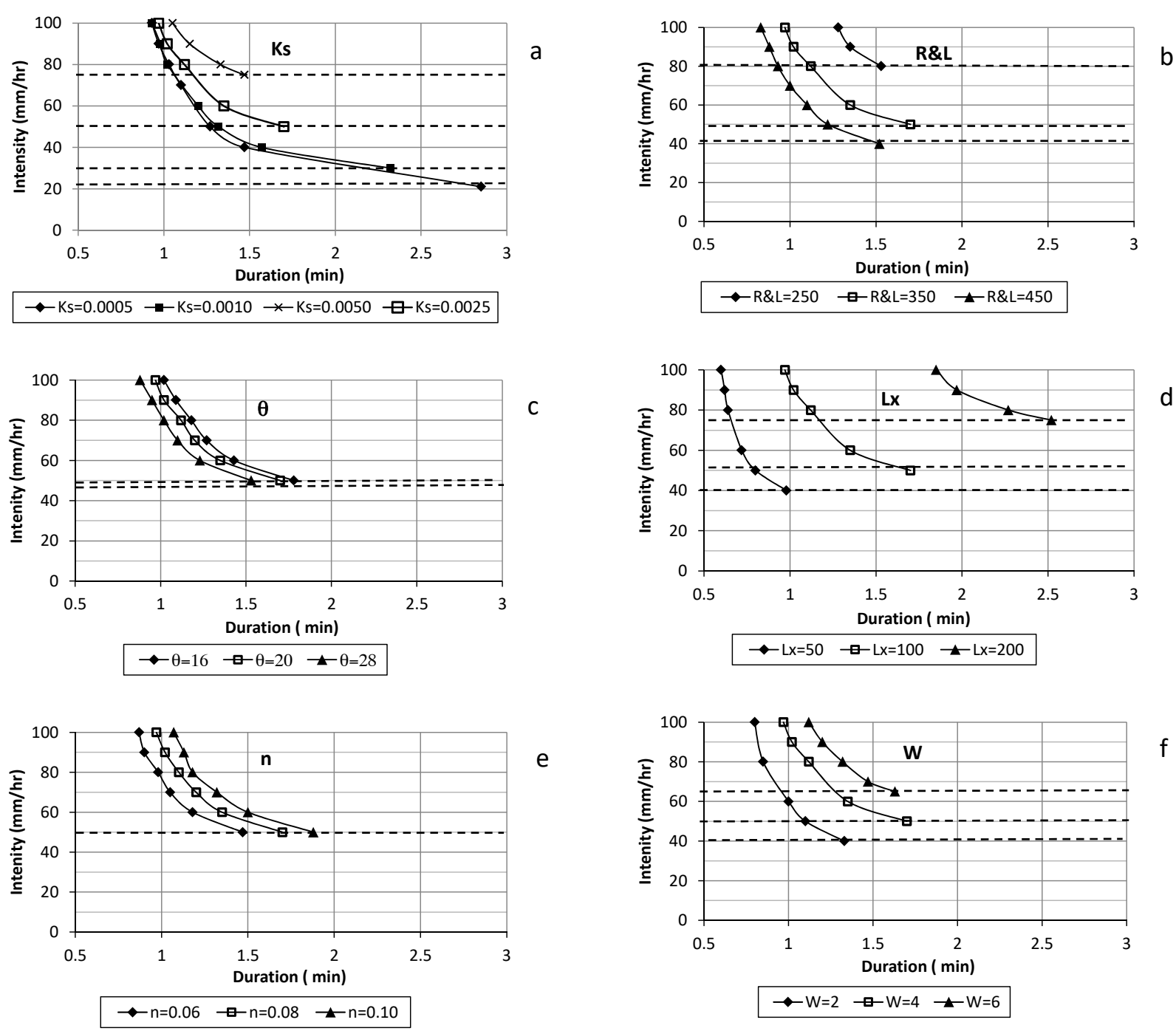

Figure 10. I-D curves for debris flow initiation by Hortonian overland flow in relation to different geometrical and hydrological parameters. For the definition of parameters see Table III 
the duration (D) of the rain event (see horizontal dotted lines). The simulations show that at intensities below this critical dotted line the overland flow water never reach the lower end of the bed due to a too high infiltration rate on its pathway compared to the supplied overland flow water and finally bed failure will be the primary triggering process.

The most obvious selected parameter for overland flow initiation is the hydraulic conductivity $K s$ Other parameters are related to geometry of the source area (see Figure 6) like length of the lateral slopes along the channel $(L)$, radius of the upstream area of the channel $(R)$ Length $(L x)$ and width $(W)$ of the channel bed, channel bed gradient $(\theta)$ and further Manning's $n$ of the bed material.

For run off initiation by Hortonian overland flow we saw in the forgoing that this triggering mechanism plays a dominant role for $K s$ values $<0.005 \mathrm{~m} \mathrm{~s}^{-1}$. Figure 10 a shows the influence of the $K s$ value on the I-D threshold curves for run off erosion initiation $\left(\mathrm{R}_{\mathrm{h}} \mathrm{E}-\mathrm{I}\right)$. The range of $K s$ values is chosen between 0.0005 and $0.005 \mathrm{~m} \mathrm{~s}^{-1}$ The Figure shows that for $K s$ values lower than $0.001 \mathrm{~m} \mathrm{~s}^{-1}$ there is nearly no effect of $K s$ on the position of the I-D curve but there is a difference in the minimum intensity values (dotted lines) below which no debris flow can occur. A slight difference can be observed for lower intensities $\left(<60 \mathrm{~mm} \mathrm{hr}^{-1}\right) \cdot$ Higher $K s$ values $(>$ $0.001 \mathrm{~m} \mathrm{~s}^{-1}$ ) have a larger influence on the I-D curves. (Figure 10a)

The simulations show that the scale of the source area and lateral slopes (R\&L), the length of the river bed (Lx) and the width of the bed (W) have the largest effect on the position of the threshold curve for the initiation of debris flow by Horton overland flow (Figure 10 b,d,f respectively). The threshold curves are less sensible for the effect of the slope gradient $\theta$ and Manning's $\mathrm{n}$ of the bed material (Figure $10 \mathrm{c}, \mathrm{e}$ respectively). 

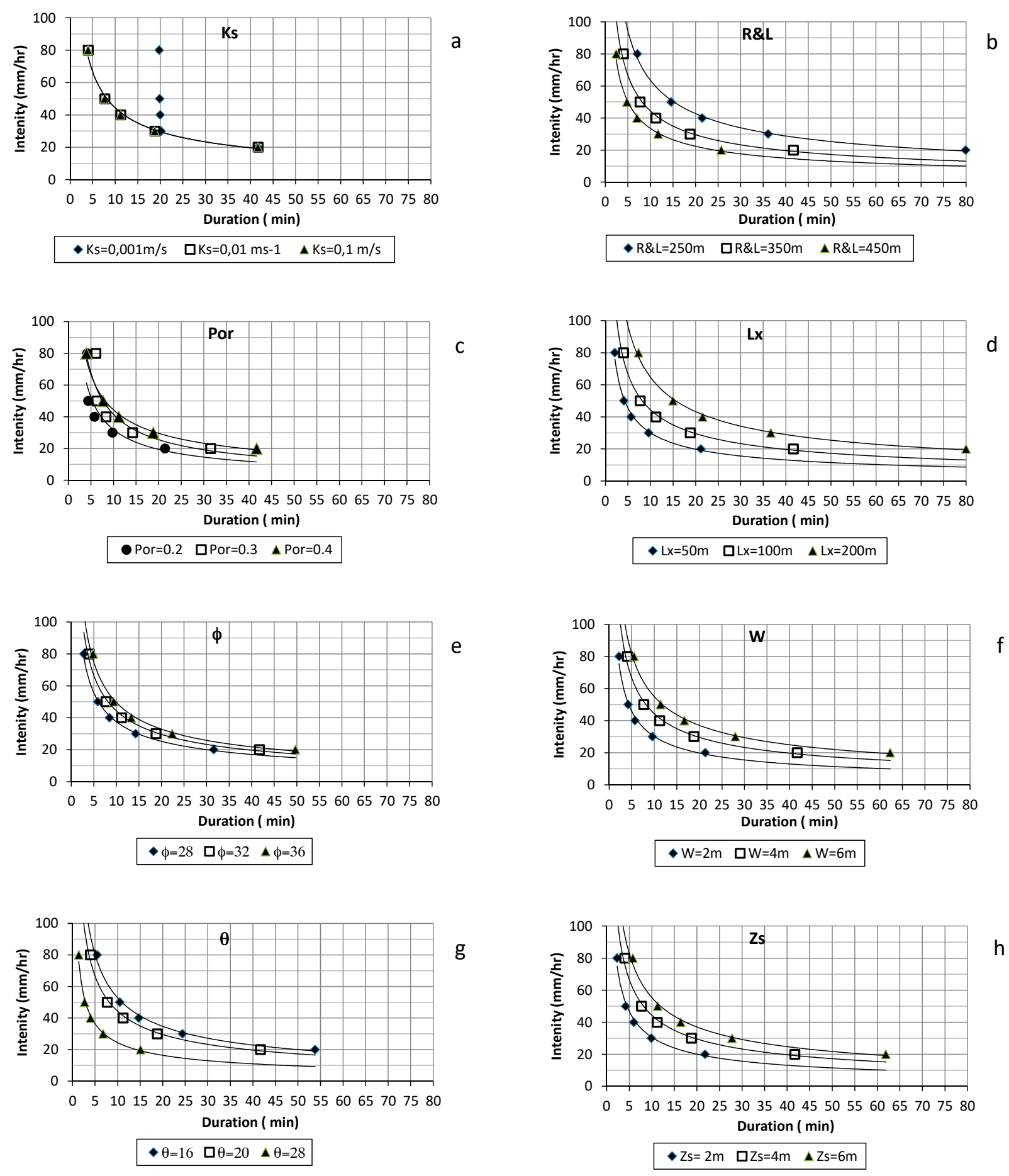

Figure 11. I-D curves for debris flow initiation by bed failure in relation to different geometrical and hydro-mechanical parameters. For the definition of parameters see Table III 
Figure 11 shows the influence of the different geotechnical and geometrical factors on the threshold values for the triggering of debris flows by bed failure. The range in $K s$ values for which bed failure (BF-I) is the dominant process is chosen between 0.001 and $0.1 \mathrm{~m} \mathrm{~s}^{-1}$ with a default value of $0.01 \mathrm{~m} \mathrm{~s}^{-1}$ The effect of the selected range in geometric values $R \& L, L x, W, \theta$, and $Z s$ ( Figure $11 \mathrm{~b}, \mathrm{~d}, \mathrm{f}, \mathrm{g}, \mathrm{h}$ respectively) seems to be more or less the same. Less effect have the porosity Por of the bed material and the $\phi$ values (Figure $8 \mathrm{c}$,e respectively). No effect has the hydraulic conductivity Ks (Figure 8a), which is related to the simplicity of the model describing instantaneous downward percolation for these high permeable bed materials. Interesting is to see that at lower Ks values (around $0.001 \mathrm{~m} \mathrm{~s}^{-1}$ ) and higher rain intensities the rate of groundwater storage and therefore the critical duration for failure is nearly the same (Figure 8a).

Our I-D curves obtained by our simulations suggest that the duration range is strongly influenced by the type of initiation. Debris flows initiated by Hortonian overland flow seems to be initiated within several minutes while debris flow initiated by bed failure within one to two hours. I-D curves find in the literature give threshold curves with a larger duration range of one to several hours. The relative quick response to debris flow initiation can be explained by the large effect we give in our simulations to the contributing slopes with sparse vegetation and low infiltration rates, which in other areas may be minor due to vegetation, and consequently higher infiltration rates and lower overland flow rates. The use of the curve number method also explains the quick response to initiation; because it does not take into account the effect of the initial moisture content with for dry soils gives larger infiltration rates and time to ponding in the first period of a rain event. It also does not simulate the travel time towards the channel. The relative quick response for channel bed failure initiation was also found by by Berti [24] dealing with nearly impermeable rock slopes in the source area. 


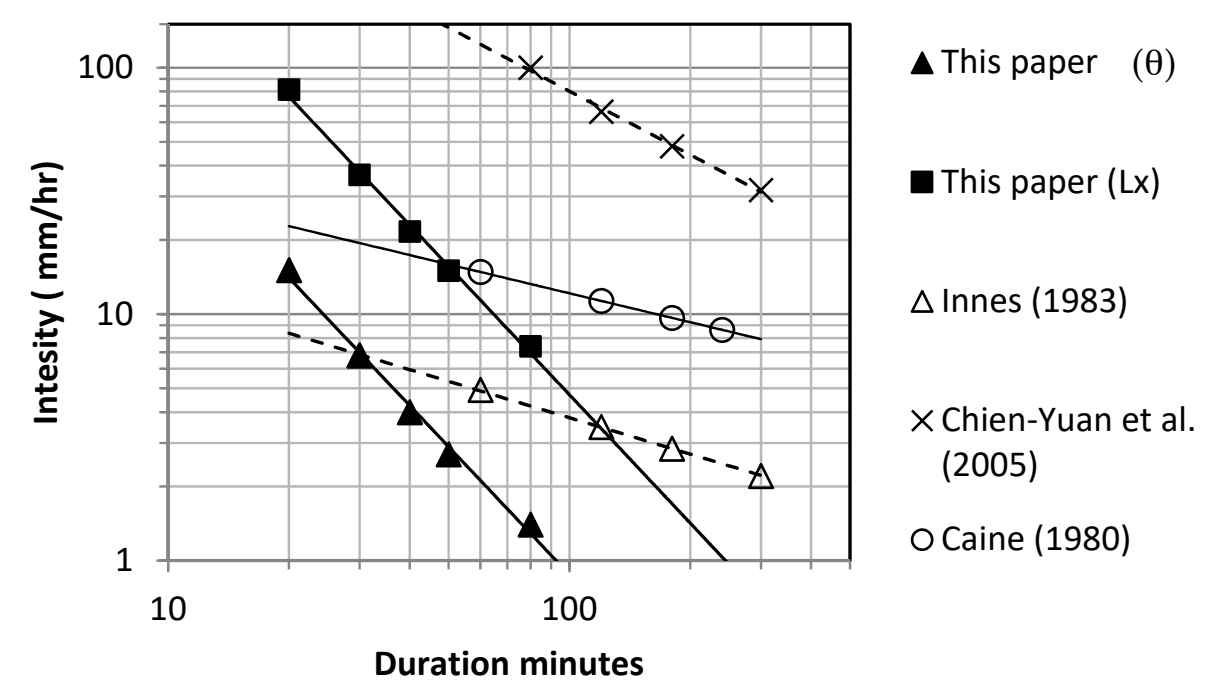

Fig 12 Ultimate variation in I-D curves as a result of our sensitivity analyzes compared to the maximum difference in I-D curves found world wide

Fig 12 compares two extreme I-D curves [38-39] and one between the two [37] obtained worldwide with the two extreme curves produced in our simulation, The curves are displayed in a loglog plot because of clarity The minimum curve in our simulation is related to the maximum channel slope $\left(28^{\circ}\right)$ and the maximum threshold curve is related to the largest length (Lx) of the channel bed. Fig. 12 shows that a simple variation of parameters for the initiation of debris flows in channel beds, gives already a relative wide range in variation compared to the range in threshold values for debris flows worldwide. The larger decline of our ID-curves compared to some of the curves worldwide may be also subscribed to the important role of the contributing slopes surrounding our hypothetical channel in the source area.

\section{Discussion}

This paper unraveled the effect of different hydro-mechanical processes on the initiation of debris flows. It is focused on the initiation in channels and it gives a detailed insight in the 
influence of different hydro-mechanical process mechanisms in the source area on the mode and sequence of debris flow initiation. It shows how different morphometric and hydrological factors, especially the hydrologic conductivity $(K s)$ and slope gradient $(\theta)$ determine the type of these process mechanisms.

Our simulations suggest that the type of initiation and related factors have also a clear influence on the values of the I-D curve as shown in Fig 10 and 11. These I-D curves, determined by our two simulated process mechanisms, Hortonian overland flow and bed failure show a relative quick response of debris flow initiation compared to wat is generally provided by the literature. Our calculations were focused on the initiation of debris flows in the source area in channel beds surrounded by slopes with scarce vegetation and rather impermeable soils. A quick response (within one hour) was also observed by Berti [24] where, as in our simulations, debris flows were initiated in the source area by the dominant effect of run-on water to the channel delivered by a bare impermeable catchment upstream.

The assessment of rainfall threshold values for debris flow initiation are based in most cases on statistical empirical approaches using large data sets without detailed knowledge of the different triggering processes and its influencing factors [2, 29].

Our quantitative approach to analyze the threshold conditions for debris flow initiation gives a more detailed insight in the effect of different parameters than the indicative parameters used in statistical techniques. Apart from the fact that no distinction is made in the mechanism of initiation, important morphometric characteristics, like channel width, slope length thickness of bed material etc, are ignored in most cases. As a consequence the prediction of rainfall threshold values and time of the initiation of debris flow for individual catchments can be very inaccurate. 
Further investigations must reveal the accuracy of both approaches to predict the initiation of debris flows.

The $\mathrm{CN}$ value, which we used in the simulation of overland flow on the contributing slopes, reflects in a lumped way the dynamic soil and land use characteristics. Especially the amount of storage of water before the time to ponding and thus the estimate of the total overland flow production of a rain event can be rather inaccurate especially for rain events of shorter durations. The use of a more detailed infiltration model incorporating the effect of the initial moisture content will give better prediction. However in this paper we did not unravel in detail the effect of these soil and land use characteristics on threshold conditions for debris flow initiation but uses a constant $\mathrm{CN}$ value as input for the run-on simulation to the channel bed. Initial moisture conditions in the channel bed, which will affect the permeability and hence the boundary conditions for initiation for overland flow initiated debris were not considered either in this paper. The effect of the initial moisture content of the bed material is minor due to the large amounts of influx of water and the relative coarse material in the channel bed.

In this paper we mentioned the transport capacity of overland flow as a limiting factor for the initiation of debris flows. On slopes $\left(< \pm 16^{\circ}\right)$ sediment concentrations are too low $(<0.2)$ to call it a debris or hyper concentrated flow. For these lower channel gradients we did not consider the effect of the delivery of extra material by side wall collapses and failure of landslide dams[1, 13], which may lead downstream to a rapid loading of the fluid and an instantaneous transformation into a debris flow

The initiation of debris flows by bed failure is also more complex since it depends on certain boundary conditions related to pore pressure development at failure and a large amount of run off water, which must be supplied during failure to keep the material moving [20, 22, 23]. 
It is interesting to analyze the potential in development further downstream of debris flows triggered by bed failure (BF-I) with high solid concentrations. On steeper slopes failure of the bed material occurs under lower groundwater heights $\left(h_{s}\right)$ and therefore after failure much additional overland flow water is needed to maintain the movement further down slope. Important is also the mechanism of erosion and erosive power of both types of debris flows further downstream in order to grow to a mature debris flow [6, 40-43].

\section{Conclusions}

Three types of hydro-mechanical processes were distinguished which can trigger debris flows in channel beds of first order source area. These are erosion and transport by intensive Horton overland flow $(\mathrm{ROh}-\mathrm{I})$, Saturation overland flow $\left(\mathrm{RO}_{\mathrm{s}}-\mathrm{I}\right)$ and by infiltrating water causing failure of channel bed material (BF-I). We were able to assess by means of a hydro-mechanical model the boundary conditions for the mode of debris flow initiation. The hydraulic conductivity of the bed sediments is an important factor controlling the type and sequence of processes triggering debris flows. At lower Ks values Hortonian overland will be the first process to start debris flows followed by bed failure or Saturation overland flow. At higher Ks values triggering by Hortonian overland flow is not possible anymore in this relatively coarse bed material and triggering by bed failure will be the dominant process if the slope gradient is steep enough $\left(>16^{0}\right)$. Therefore the slope gradient of the channel bed is a second important factor controlling the type of hydomechanical triggering. On gentler slopes which remain stable under saturated conditions, Saturation overland flow might create debris flows if slope gradient is not too gentle and therefore sediment concentration too low to call it a debris flow.

We further analyzed also the effect of different important morphometric and hydro-mechanical parameters on meteorological thresholds for triggering debris flows by overland flow or bed 
failure respectively. With respect to overland flow triggering, the morphometric factors related to the size of the source area and width and length of the channel bed have the largest influence on position of the I-D curves. Meteorological thresholds for bed failure triggering are also sensitive to morphometric parameters while the hydro mechanical parameters have relative less influence on these threshold values.

\section{References}

[1]Zhuang, J.; Cui, P Peng J.; Hu, K.; Iqbal, J. Initiation process of debris flows on different slopes due to surface flow and trigger-specific strategies for mitigating post-earthquake in old Beichuan County, China. Environmetal. Earth Sciences. 2013 68, 1391-1403; DOI 10.1007/s12665-012-1837-2.

[2]Cuomo, S.; Della Sala, M. Rainfall-induced infiltration, runoff and failure in steep unsaturated shallow soil deposits. Eng. Geol. 2013, 162, 118-127.

[3]Cuomo, S.; Della Sala, M.; Novita, A. Physically based modelling of soil erosion induced by rainfall in small mountain basins. Geomorph. 2015, 243, 106-115.

[4] Berti, M.; Genevois, R.; Simoni, S.; Tecca P.R. Field observations of a debris flow event in the Dolomites. Geomorph. 1999, 29, 265-274.

[5]Armanini, A.; Gregoretti C. Triggering of debris flow by overland flow: a comparison between theoretical and experimental results. Proceedings 2nd International Conference on Debris flow Hazards Mitigation, Taipei, Taiwan; Wiezczorek, Naeser Eds. 2000, 117-124.

[6]Takahashi, T.. Initiation and flow of various types of debris flow. Proceedings 2nd International Conference on Debris Flow Hazards Mitigation: Mechanics, Prediction and Assessment, Taipei, Taiwan; Wieczoreck, Naeser ,Eds. 2000, 15-25 
[7] Coe, J.A.; Kinner, D.A.; Godt, J.W.. Initiation conditions for debris flows generated by runoff at Chalk Cliffs, central Colorado. Geomorph. 2008, 96, 270-297.

[8] Yu, B. Research on the prediction of debris flows triggered in channels. Natural Hazards, 2011, 58, 391-406; DOI 10.1007/s11069-010-9673-8.

[9] Van Asch, Th.W.J.; Tang, C.; Zhu, J; Alkema. D. An integrated model to assess critical rainfall thresholds for the critical run-out distances of debris flows. Nat. Hazards, 201470 (1), 299-311.

[10] Tang, C.; Rengers, N.; Van Asch, T.W.J.; Yang, Y.H.; Wang, G.F. Triggering conditions and depositional characteristics of a disastrous debris-flow event in Zhouqu city, Gansu Province, northwestern China. Nat. Hazards Earth Syst. Sci., 2011., 11, 2903-2912.

[11] Cui, P.; Zhou, G.G.D.; Zhu, X.H.; Zhang, J.Q.. Scale amplification of natural debris flows caused by cascading landslide dam failures. Geomorph. 2013, 182 173-189.

[12] Zhou, G.G.D.; Cui, P.; Chen, H.Y.; Zhu, X.H.; Tang J.B.; Sun, Q.C. Experimental study on cascading landslide dam failures by upstream flows. Landslides 2013, 10 (5), 633-643.

[13] Hu, W.; Xu, Q.; van Asch, T.W.J.; Zhu, X.; Xu, Q.Q.. Flume tests to study the initiation of huge debris flows after the Wenchuan earthquake in S-WChina. Eng. Geol., 2015a, 182, $121-129$.

[14] Cannon, S.H.; Kirkham, R.M.; Parise, M. Wildfire-related debris flow initiation processes, Storm King Mountain, Colorado. Geomorph. 2001, 39, 171-188.

[15] Hungr, O.; Evans, S.G.; Bovis, M.J.; Hutchinson, J.N. A review of the classification of landslides of the flow type. Environmental. and Engineering. Geosciences., 2001, 7(3), 221238. 
[16] Malet, J-P.; Laigle, D.; Remaître, A.; Maquaire, O. Triggering conditions and mobility of debris flows associated to complex earthflows. Geomorph., 2005, 66, 215-235.

[17] Cascini, L.; Cuomo, S.; Della Sala, M. Spatial and temporal occurrence of rainfall induced shallow landslides of flow type: a case of Sarno-Quindici, Italy.Geomorph., 2011 126(1-2), 148-158.

[18] Zhang, S.; Zhang, L.M.; Peng, M.; Zhang, L.L.; Zhao, H.F.; Chen, H.X. Assessment of risks of loose landslide deposits formed by the 2008 Wenchuan earthquake. Nat. Hazards and Earth Syst. Sci 2012. 12, 1381-1392; DOI:10.5194/nhess-12-1381-2012

[19] Iverson, R.M.; Reid, M.E.; LaHusen, R.G. Debris flow mobilization from landslides. Ann. Rev. of Earth Plan. Sci. 1997, 25, 85-138.

[20] Fuchu, D.; Lee,C.F.; Sijing, W. Analysis of rainstorm-induced slide-debris flows on natural terrain of Lantau Island, Hong Kong. Eng. Geol., 1999, 51, 279-290.

[21] Gabet, E.J.; Mudd, S.M. The mobilization of debris flows from shallow landslides. Geomorph., 2006, 74, 207-218.

[22] Van Asch, Th.W.J.; Malet, J-P. Flow-type failures in fine-grained soils: an important aspect in landslide hazard analysis. Nat, Hazards and Earth Syst Sci 2009, 9, 1703-1711.

[23] Hu, W.; Donga, X.J.; Xua, Q.; Wang G.H.; Van Asch, T.W.J.; Hicher, P.Y.. Initiation processes for overland flow generated debris flows in theWenchuan earthquake area of China. Geomorph., 2016, 253, 468-47.

24] Berti, M.; Simoni, A.. Experimental evidences and numerical modelling of debris flow initiated by channel runoff. Landslides, 2005, 2, 171-182; DOI: 10.1007/s10346-005-00624. 
[25] Kean, J. W.; McCoy, S.W.; Tucker, G.E.; Staley, D.M.; Coe J.A. Runoff-generated debris flows: Observations and modeling of surge initiation, magnitude, and frequency. $J$. Geophys. Res. Earth Surf., 2013, 118, 2190-2207.;DOI:10.1002/jgrf.20148.

26] Hu, W.; Xu, Q.; Wang, G.H.; van Asch, T.W.J.; Hicher, P.Y. Sensitivity of the initiation of debris flow to initial soil moisture. Landslides, 2015, 12, 1139-1145; DOI: 10.1007/s10346014-0529-2.

[27] Liu, C.; Dong, J.; Peng, Y.; Huang, H. Effects of strong ground motion on the susceptibility of gully type debris flows. Eng. Geol. 2009. 104(3-4), 241-253.

[28] Chang, T.C.; Chien, Y.H. The application of genetic algorithm in debris flow prediction. Environmental Geology., 2007 53, 339-347.

[29] Tiranti,D.; Bonetto, S.; Mandrone, G. Quantitative basin characterization to refine debrisflow triggering criteria and processes: an example from the Italian Western Alps. Landslides 2008, $5,45-57$.

[30] Yu, B.; Li,L.; Wu, Y.; Chu, S. A formation model for debris flows in the Chenyulan River Watershed, Taiwan. Natural Hazards 2013, 68, 745-762; DOI: 10.1007/s11069-013-0646-6.

[31] Smith. G.N.;Smith, I.G.N. Elements of Soil Mechanics $7^{\text {th }}$ ed.;Blackwell Science Ltd Oxford, UK, 1988; 494 pp.; ISBN0-632-04126-9.

[32] Hendriks M.R. Introduction to physical Hydrology, $1^{\text {st }}$ ed. Oxford University press: Oxford ,UK, 2010; 331 pp.; ISBN 978-0-19-929684-2.

[33] Chow, V.T.; Maidment, D.R.; Mays, L.W.. Applied hydrology. McGraw-Hill Book company: New York, USA, 1988, 572 pp. ISBN 0-07-010810-2.

[34]Rickenmann, D.. Hyperconcentrated flow and sediment transport at steep slopes. Journal of Hydraulic Engineering 1991, 117 (11), 1419-1439. 
[35] Rickenmann, D. Comparison of bed load transport in torrents and gravel bed streams. Water Resources Research 2001, 37(2), 3295-3305.

[36] USDA-SCS. National Engineering Handbook, Section 4:Hydrology 1985, USDA-SCS. Washington D.C,USA.

[37] Caine, N.; The rainfall intensity duration control of shallow landslides and debris flows. Geogr. Ann. A Phys. Geogr. 1980, 62(1/2), 23-27.

[38 Innes, J.L. Debris flows. Progr. Phys. Geogr.1983, 7(4,) 469-501; DOI:.org/10.1177/030913338300700401

39] Chien-Yuan.;C.;Tien-Chien, C.; Fan-Chieh,Y.;Wen-Hui,Y.;Chun-Chieh,T. Rainfall duration and debris-flow initiated studies for real-time monitoring. Environ. Geol. 2005, 47, pp. 715724, DOI: $10.1007 / \mathrm{s} 00254-004-1203-0$

[40] McDougall, S.; Hungr, O. Dynamic modelling of entrainment in rapid landslides. Can. Geotech. J. 2005, 42, 1437-1448.

[41] Medina, V.; Hürlimann. M.; Bateman, A.. Application of FLATModel, a 2D finite volume code, to debris flows in the northeastern part of the Iberian Peninsula. Landslides 2008, 5, $127-142$.

[42] Iverson, R.M,.;Reid, M.E.; Logan, M.; LaHausen, R.G.; Godt, J.W.; Griswold, J.P. Positive feedback and momentum growth during debris-flow entrainment of wet bed sediment. Nature Geosciences. 2011. 4, 116-121.

[43] Quan Luna, B.; Remaître, A.; Van Asch, Th.W.J.; Malet, J-P,; Van Westen, C.J. Analysis of debris flow behavior with a one dimensional run-out model incorporating entrainment. Eng. Geol. 2012, 128, 63-75. 
$\underline{\text { Individual contribution of authors }}$

Van Asch, Yu and Hu conceived and designed the experiments; Yu performed the hydro-mechanical measurements on the materials and performed the experiments; Van Asch and Yu analyzed the data; Van Asch did the modelling and wrote the paper." 